\title{
Presupuestos teórico-jurídicos del capital social de las cooperativas en Cuba: apuntes para un debate
}

\author{
(Theoretical and legal foundations of cooperative's share
} capital in Cuba: notes for a debate)

\author{
Yulier Campos Pérez ${ }^{1}$ \\ Universidad Central «Marta Abreu» de Las Villas. Santa Clara (Cuba)
}

Sumario: I. Introducción. II. La cooperativa como institución jurídica: su carácter de empresa. III. El capital social cooperativo: sus funciones. Distinción de las que cumple en una sociedad mercantil. IV. El capital social cooperativo: aciertos y desaciertos de su novísima regulación en Cuba. V. Conclusiones. VI. Bibliografía y legislación.

Summary: I. Introduction. II. Cooperative as a legal institution: its character as an enterprise. III. Functions of the share capital in cooperatives and its differences with the share capital of companies. IV. The cooperative's share capital: successes and failures of its newest regulation in Cuba. V. Conclusions. VI. Bibliography y legislation.

Resumen: El presente artículo se centra en el análisis del capital social cooperativo y su regulación jurídica en Cuba. Se comienza delimitando el carácter de empresa de la cooperativa, así como la necesidad que esta posee de contar con recursos económicos para cumplir sus fines. En lo adelante se explican las aportaciones al capital social y sus funciones, así como la regulación (aciertos y desaciertos) que posee el mismo en las nuevas normas jurídico-cooperativas aprobadas en Cuba. El objetivo general del presente artículo estriba en: analizar las reglas teórico-doctrinales esenciales que rigen el capital social cooperativo en pos de su concreción en el ordenamiento jurídico cubano. Los métodos de la investigación jurídica empleados fueron el teórico-jurídico y el exegético-analítico. De esta manera se contribuye al perfeccionamiento de las bases teórico-jurídicas del capital social cooperativo a nivel internacional y en especial en Cuba.

Palabras clave: empresa cooperativa, capital social, regulación jurídica.

1 Profesor Auxiliar de Derecho Cooperativo, Derecho de Autor y Propiedad Industrial. Departamento de Derecho. Facultad de Ciencias Sociales. Universidad Central «Marta Abreu» de Las Villas. Santa Clara, Cuba. Miembro de la Asociación Internacional de Derecho Cooperativo, Universidad de Deusto. E-mail: ycperez@uclv.edu.cu 
Abstract: This article focuses on the analysis of cooperative share capital and its legal regulation in Cuba. It begins by delimiting the cooperative's character as an enterprise, as well as its need for economic resources to fulfill its purposes. Later on, the contributions to the share capital and its functions are explained, as well as its regulation (successes and failures) in the new cooperative-legal norms approved in Cuba. The general objective of this article is: to analyze the essential theoretical-doctrinal rules that govern the share capital cooperative in pursuit of its concretion in the Cuban legal system. The legal research methods used were the theoretical-legal and the exegetical-analytical. In this way, it is contributed to the improvement of the theoretical-legal bases of the cooperative share capital at international level and especially in Cuba.

Keywords: cooperative enterprise, share capital, legal regulation. 


\section{Introducción}

Las cooperativas constituyen organizaciones colectivas «especiales» que se instituyen en función de los principios y valores cooperativos, esto las hace distintas de la asociación y la sociedad. Aunque en estas el vínculo asociativo es un componente esencial, no es menos cierto que necesitan realizar actividades empresariales que garanticen su sostenibilidad. Por tanto, poseen una «doble naturaleza». Para cumplir con sus encomiendas sociales, culturales, económicas, comunitarias, etc. realizan actividades empresariales, es lo que se conoce como empresa cooperativa.

Para cumplir sus fines y desarrollar su objeto social necesitan de recursos económicos; estos pueden provenir de sus propios asociados, la gestión común o de terceros. La aportación que realizan los socios constituye una forma de participar los mismos en el esfuerzo colectivo para satisfacer sus propias necesidades, las del grupo y las de la sociedad; contribuye al fortalecimiento del sentido de pertinencia por el trabajo en común, por tanto, no solo poseen un valor económico sino también social.

La totalidad de estas aportaciones forman el capital social cooperativo, el que se distingue en este contexto del capital de otras organizaciones, tal es el caso de las sociedades mercantiles. Aquí el capital sirve a la persona, es instrumental, esto se corrobora con el análisis de sus funciones. Esto refuerza la idea de considerar a la cooperativa como una empresa distinta.

En Cuba las normas que regulan las cooperativas han sido actualizadas recientemente, sin embargo, aún persiste la asistematicidad en su diseño, pues varían de acuerdo a la tipología de las cooperativas, sean agraria o no. En el caso del capital social dicha asimetría es manifiesta pues no están reconocidas con carácter totalizador las reglas legales que delimitan la institución y los elementos que la conforman. Lo anterior presupone la necesidad del análisis de las reglas teóricas que rigen el capital social de las cooperativas en la doctrina internacional y la necesidad de su concreción en el ordenamiento jurídico nacional. Para ello se utilizaron los siguientes métodos de la investigación jurídica:

Teórico-jurídico: el que permitió un adecuado análisis bibliográfico y doctrinal del capital social, las aportaciones a este y el patrimonio cooperativo. Logrando que la investigación esté dotada de un basamento teórico-conceptual profundo.

Exegético-analítico: en el análisis de las normas jurídico- cooperativas cubanas, y complementarias. 


\section{La cooperativa como institución jurídica: su carácter de empresa}

Delimitar a la cooperativa desde el punto de vista jurídico es una tarea complicada, debido a que no existe un juicio unánime - doctrinal ni legal — con respecto a la naturaleza que esta adopta.

Ha podido constatarse que prevalecen tres criterios fundamentales ${ }^{2}$ para delimitar la naturaleza jurídica de esta: la que la considera una asociación ${ }^{3}$, la que la considera una sociedad mercantil ${ }^{4}$ y la que la considera como una categoría autónoma o especial, criterio este último que el autor comparte puesto que la cooperativa, aunque posee rasgos de una u otra figura, no se ajusta directamente a ninguna.

En este último sentido García Müller considera que las cooperativas no son (...) simples asociaciones de personas con una empresa, ni (...) empresas económicas cuyos titulares son un grupo de personas. Es decir, ni una ni otra naturaleza predomina. Las cooperativas son simultáneamente las dos cosas: asociaciones de personas y empresas económicas; en eso consiste su «doble naturaleza»5. Criterio este que compartimos, puesto que, aunque a sus miembros los mueve el interés de trabajar colectivamente $-\mathrm{y}$ a veces la necesidad-, para lograr sus objetivos lo tienen que hacer mediante la realización de

2 Enrique Gadea, Fernando Sacristán y Carlos Vargas, Régimen jurídico de la sociedad cooperativa del siglo XXI. Realidad actual y propuestas de reforma, Editorial Dykinson, Madrid, 2009: 70-83

3 Los autores que reconocen a las cooperativas como una asociación (V. José Castán Tobeñas, Derecho civil español. Común y foral, t. IV, Editorial. Reus, Madrid, 1985: 586 y Luis Díez-Picazo, y Antonio, Gullón, Sistema de Derecho Civil, Vol. II, Editorial. Tecnos, 1999: 451) parten del hecho de que en las cooperativas no existe ánimo de lucro y persiguen un fin social, por tanto y por exclusión de las sociedades, pueden considerarse como un tipo de asociación. Sin embargo, esta aseveración no es suficiente para considerar a las cooperativas como asociaciones, es necesario partir del hecho de que en ambas concurre un número plural de personas, pero los fines de una u otra difieren sustancialmente. Las cooperativas realizan una actividad empresarial, económica, mientras las asociaciones no.

4 Esta tendencia se ha reforzado con los procesos de mercantilización de las cooperativas, dados por la introducción de los llamados socios de capital, el voto plural, así como el funcionamiento de sociedades mercantiles simulando cooperativas. Sin embargo, pese a estas cuestiones, el cooperativismo no puede reducirse a los estrechos marcos del mercantilismo, sus fines son aún más ambiciosos socialmente, aunque para conseguirlos han de desarrollar una actividad empresarial, estas deber funcionar con apego a los principios cooperativos, los beneficios se reparten en función a la actividad realizada y no en función de las aportaciones.

5 Alberto García Müller, Derecho Cooperativo y de la economía social y solidaria, Editorial Mérida, Buenos Aires, 2019. 
una actividad empresarial. De otra manera, dichas necesidades quedarían en meras aspiraciones. Sin embargo, la actividad empresarial no constituye fin en sí misma, esta posee carácter instrumental, pues la verdadera finalidad está no solo en la satisfacción de las necesidades individuales, colectivas sino también en las de la comunidad y la sociedad.

En este propio orden Aranzadi Tellería ${ }^{6}$ considera que la cooperativa es una empresa con todas sus consecuencias, no una sociedad benéfica (...). El lucro en las cooperativas no tiene correspondencia con el característico de las sociedades, los eventuales resultados positivos de la actividad cooperativizada llegan a trascender del propio ente con un claro reflejo colectivo y social.

Es entonces un ente distinto de la sociedad y de la asociación pues tiene características que la apartan de tales instituciones y su finalidad es sustancialmente diferente. Tiene de la asociación la concurrencia de un número plural de sujetos con intereses colectivos y sociales, sin embargo, realiza actividades empresariales y sus fines no son únicamente sociales, esto las distingue de aquellas.

Dicha especialidad se refuerza con la influencia de los valores y principios cooperativos reconocidos internacionalmente por la Alianza Cooperativa Internacional $(\mathrm{ACl})$. Estos constituyen lineamientos por medio de los cuales, se rigen las cooperativas y ponen en práctica sus valores $^{7}$ y que en esencia desde hace 150 años son practicados por sus miembros.

El entorno legislativo internacional referente a las cooperativas y su naturaleza jurídica también es diverso. Por ejemplo, es reconocida como sociedad en las normas cooperativas de Alemania ${ }^{8}$, España ${ }^{9}$, y Brasil. ${ }^{10}$ Por su parte, y en oposición a esta vertiente, es reconocida

6 Dionisio Aranzadi Tellería, «Los valores cooperativos en el umbral del año 2000», Anuario de Estudios Cooperativos, Bilbao, (1994): 128

7 La Declaración de Identidad Cooperativa de la $\mathrm{ACl}$ señala que las cooperativas se basan en los valores de ayuda mutua, responsabilidad, democracia, igualdad, equidad y solidaridad. Siguiendo la tradición de sus fundadores sus miembros creen en los valores éticos de honestidad, transparencia, responsabilidad social y preocupación por los demás.

8 El Art. 1 de la Ley de Cooperativas de Alemania sostiene que las cooperativas son sociedades... Ley Cooperativa Alemana, de 19 de agosto de 1994, recuperada de http://www.dgrv.org/ en fecha 9 de enero de 2020

9 El Art. 1.1. de la Ley de Cooperativas española reconoce que la cooperativa es una sociedad... Ley de Cooperativas de España, Ley 27, de 16 de julio de 1999. (BOE núm. 170, de 17 de julio de 1999).

10 El Art. 4 LEI N. ${ }^{\circ} 5.764$ en Brasil reconoce As cooperativas são sociedades de pessoas... (Official Gazette, 1971-12-16, 40p. (COOP) de 16 de diciembre de 1971. 
como asociación en las leyes de Uruguay ${ }^{11}$ y la Ley Marco para las Cooperativas de América Latina ${ }^{12}$. Por último, es reconocida como una categoría sui generis en las normas jurídicas de Portugal ${ }^{13}$ y Honduras ${ }^{14}$.

Sin embargo, a partir de este propio análisis puede sostenerse que incluso las legislaciones que no le reconocen a la cooperativa una forma jurídica especial si incluyen determinados caracteres que las distinguen de la sociedad y la asociación, respectivamente. Por tanto, no es suficiente examinar solo si en la legislación se reconoce como sociedad, asociación, etc. es necesario verificar hasta qué punto se reconocen estas características distintas, a saber, ausencia de ánimo de lucro, naturaleza especial, igualdad, etc.

Según Naranjo Mena las características de las cooperativas que marcan las diferencias radicales con otras formas empresariales son la ausencia del fin de lucro, la variabilidad del capital y la irrepartibilidad de las reservas sociales ${ }^{15}$. Aunque coincidimos con que estas cuestiones distinguen a las cooperativas de otras organizaciones colectivas, consideramos que no son las únicas.

En este propio sentido, la «Ley marco para las cooperativas en América Latina» (2009), establece que las cooperativas poseen los siguientes caracteres: ilimitación y variabilidad del número de socios, plazo de duración indefinido, independencia religiosa, racial y político partidaria, igualdad de derechos y obligaciones entre los socios, reconocimiento de un solo voto a cada socio, independientemente de sus aportaciones, irrepartibilidad de las reservas sociales y variabilidad e ilimitación del capital.

En lo anterior no solo se reconocen algunos elementos que rozan con los principios, además se incluyen caracteres que refuerzan, so-

11 El Art. $4 .^{\circ}$ de la Ley N. ${ }^{\circ} 18.407$ Sistema cooperativo en Uruguay. De limita que las cooperativas son asociaciones autónomas de personas... Ley N. ${ }^{\circ} 18.407$ Sistema Cooperativo. República Oriental del Uruguay. De la Cámara de Senadores, de fecha 24 de octubre de 2008. (Diario Oficial N. ${ }^{\circ} 27612$ de 14 noviembre de 2008).

12 El Art. 3 la Ley Marco para las Cooperativas de América Latina reconoce que las cooperativas son asociaciones de personas ...

13 El Art. 2. ${ }^{\circ}$ de la Lei n. ${ }^{\circ} 119 / 2015$ Código Cooperativo en Portugal regula que las cooperativas são pessoas coletivas autónomas... Ley 119/2015, de 31 de agosto. De la Asamblea de la República de Portugal, de 31 de agosto de 2015. (Diario de la República n. $\left.{ }^{\circ} 169 / 2015\right)$.

14 El Art. 6. de la Ley de Cooperativas en Honduras (Decreto No. 146 de 2019) establece que las Cooperativas, son organizaciones autónomas de personas...) (Diario Oficial de la Republica de Honduras).

15 Carlos Naranjo Mena, "Concepto y naturaleza jurídica de la cooperativa», en Derecho Cooperativo Latinoamericano, ed. por José Ernani de Carvalho Pacheco (Curitiba Juruá Editora, 2018): 65 
bre todo en el ámbito patrimonial, la diferencia de las cooperativas con otras organizaciones colectivas como las sociedades mercantiles capitalistas, tal es el caso de los efectos que genera la aportación, la variabilidad e ilimitación del capital y la imposibilidad del reparto de las reservas sociales.

Ahora bien, en Cuba el fenómeno cooperativo desde el 2012 se desarrolla en dos ámbitos esenciales: el cooperativismo agropecuario y el no agropecuario.

Para el caso de las cooperativas agrarias rige ${ }^{16}$ el Decreto-Ley No. 365 «De las cooperativas agropecuarias» de 22 de octubre de 2018 y el Decreto No. 354 «Reglamento del Decreto-Ley de las cooperativas agropecuarias» de 18 de diciembre de 2018. Mientras que las no agropecuarias se regulan mediante el Decreto-Ley No. 366 «De las cooperativas no agropecuarias» de 19 de noviembre de 2018, el Decreto No. 356 «Reglamento de las cooperativas no agropecuarias» de 2 de marzo de 2019 y sus normas complementarias ${ }^{17}$.

No obstante, y pese a esta disparidad, acertadamente, la Constitución de la República de Cuba proclamada el 10 de abril de 2019 reconoce en su artículo 22 inciso b) a la propiedad cooperativa. En tal sentido establece que la misma es «la sustentada en el trabajo colectivo de sus socios propietarios y en el ejercicio efectivo de los principios del cooperativismo» ${ }^{18}$. Pese a que aún reconoce a la cooperativa como una mera forma de propiedad, es de destacar que ya no es en los estrechos marcos del cooperativismo agropecuario, puesto que no delimita los ámbitos en que esta se puede desarrollar. También es válido reconocer que las mismas se sustentan en los principios del cooperativismo, esto favorece la materialización y configuración jurídica de su particular identidad.

Sin embargo, la asimetría que presentan las normas especiales, complejiza el tratamiento de las cooperativas y las figuras jurídicas que las acompañan. No obstante, pueden buscarse fórmulas que acompañen a unas y otras cooperativas, puesto que los fines coinciden, en

16 Ambas normas jurídicas se publicaron en (Gaceta Oficial No. 37 Ordinaria de 24 de mayo de 2019).

17 Las normas complementarias de estas son: la Resolución No. 36 de la Ministra de Finanzas y Precios, sobre el tratamiento de precios, tributario, financiero y contable de las cooperativas no agropecuarias y la Resolución No. 362 de la Ministra de Finanzas y Precios, respecto al pago del Impuesto sobre Ingresos Personales de los trabajadores contratados. Todas publicadas en la (Gaceta Oficial No. 63 Ordinaria de 30 de agosto de 2019).

18 Art. 22 b) Constitución de la República de Cuba proclamada el 10 de abril de 2019. (Gaceta Oficial No. 5 Extraordinaria de 10 de abril de 2019). 
buena medida, para ambos escenarios. La cooperativa como institución jurídica es una, más allá de las particularidades que su objeto impone.

El mentado Decreto-Ley No. 365 «De las cooperativas agropecuarias» reconoce que "la cooperativa agropecuaria es una organización económica y social que forma parte del sistema de producción agropecuaria y forestal; su objetivo general es la producción de bienes, fundamentalmente agropecuarios y su comercialización, así como la prestación de servicios mediante la gestión colectiva para la satisfacción del interés social y el de los cooperativistas» ${ }^{19}$.

Es la primera vez que en Cuba se define legalmente a la cooperativa agropecuaria con carácter totalizador. Esto supone un avance, pues se identifican rasgos y pautas comunes para los tres tipos de cooperativas que se desenvuelven en el país en este ámbito.

Por otra parte, y al considerarla una "organización», no se delimita la naturaleza jurídica de la cooperativa; dicha norma no adopta una postura en cuanto a si esta es una asociación, una sociedad o una forma sui generis. Sin embargo, es válido resaltar que la Ley 54 de 27 de diciembre de 1985 «Ley de Asociaciones» en Cuba excluye a las cooperativas de sus predios. Similar posición adopta el Código de Comercio Español hecho extensivo a Cuba mediante Real Decreto de 22 de agosto de 1885 y vigente aún en parte. Este dispone la exclusión de las cooperativas, excepto cuando realizaran actos de comercio. Por tanto, el entorno legislativo en Cuba, en nuestro criterio, se decanta hacia el reconocimiento de una naturaleza jurídica "distinta» de las cooperativas, o por lo menos diferente de las otras figuras colectivas que reconoce. Pese a ello, lo ideal sería reconocerlo de manera expresa sin que quedes dudas de la posición adoptada, esto es lo apropiado desde el punto de vista técnico- jurídico, pues permite establecer el régimen jurídico exacto a todas las relaciones jurídicas que rodean a las cooperativas.

Una situación similar ocurre en el ámbito no agropecuario, así el Decreto-Ley No. 366 «De las cooperativas no agropecuarias» de 19 de noviembre de 2018 dispone en el artículo 2.1. que «la cooperativa es una organización con fines económicos y sociales, que se constituye voluntariamente sobre la base del aporte de bienes y derechos y se sustenta en el trabajo de sus socios» 20 . Su objetivo general es "la producción de bienes y la prestación de servicios mediante la gestión colectiva para la satisfacción del interés social y el de los socios...» ${ }^{21}$.

19 Art. 2.1 Decreto-Ley No. 365 «De las cooperativas agropecuarias...

20 Art. 2.1 Decreto-Ley No. 366 «De las cooperativas no agropecuarias...

21 Cfr. Art. 2.2 Decreto-Ley No. 365 «De las cooperativas agropecuarias... 
Tampoco queda expresa aquí la naturaleza jurídica de la cooperativa, - siguiendo la sistemática de su norma predecesora ${ }^{22}$-; en ambas normas jurídicas se considera "organización» sin delimitar que forma adopta esta persona jurídica. Sin embargo, el reconocimiento jurídico de "las especificidades de la forma socioeconómica cooperativa, permitiría diferenciarla de otras formas de organización para la obtención de los bienes y servicios que requerimos para satisfacer nuestras necesidades ${ }^{23}$.

Unido a esto, y con influencia en la naturaleza jurídica cooperativa, a los miembros de las cooperativas no agropecuarias se les denomina socios $^{24}$, lo que hace pensar que estamos en presencia de una sociedad mercantil puesto que en este marco este es el nombre que recibe sus miembros ${ }^{25}$. En oposición a ello a los miembros de las cooperativas agrarias se les denomina cooperativistas ${ }^{26}$. En nuestro criterio, esto último estaría en consonancia con el reconocimiento de una naturaleza jurídica distinta a la cooperativa, puesto que siendo así, las personas que la integran también recibirían una denominación diferente.

Pese a la no delimitación de la particular naturaleza jurídica -y su consecuente influencia sobre la definición- la normativa cooperativa nacional reconoce que estas poseen fines económicos y sociales. No basta solo cumplir con las actividades empresariales que el objeto social

22 Art. 2.1 Decreto Ley No. 305, «De las Cooperativas no agropecuarias», de 15 de noviembre de 2012. (Gaceta Oficial 053 Extraordinaria de 11 de diciembre de 2012).

23 Sergio Reyes Lavega, Las especiales características de las cooperativas. (Fundación Friedrich Ebert, República Dominicana, 2012). 1

24 Cfr. Artículo 23.1. Decreto-Ley No. 366 «De las cooperativas no agropecuarias... sostiene que son socios fundadores los que se incorporan como tales en el acto de constitución de la cooperativa. 2. Cuando la cooperativa se constituya, conforme con lo establecido en el apartado 2 del Artículo 12 del presente Decreto-Ley, son socios fundadores, preferentemente, los que son trabajadores de esas entidades. 3. Las personas que se incorporen a una cooperativa después de su constitución pueden hacerlo como socios o como socios a prueba, según lo establecido en el presente Decreto-Ley y su Reglamento.

25 En similar sentido sostiene Mesa Tejeda que «el legislador utilizó una fórmula muy genérica al calificarla como organización (...) Sin embargo, otros artículos del texto legal nos conducen a pensar en la posibilidad de concebir a la cooperativa como una sociedad mercantil, ya que se utiliza el término de socios y no el de miembros o asociados...». Natasha Teresa Mesa Tejeda, "Reflexiones críticas en torno a la regulación de las cooperativas no agropecuarias en Cuba», Boletín de la Asociación Internacional de Derecho Cooperativo No. 48, Universidad de Deusto, Bilbao, (2014):231

26 Art. 3. Decreto-Ley No. 365 «De las cooperativas agropecuarias... establece que se considera cooperativista, a los efectos del presente Decreto-Ley, a toda persona natural socia de una cooperativa agropecuaria. 
de la cooperativa demande, sino que es necesario satisfacer determinas necesidades que desbordan lo estrictamente económico.

Tomando en cuenta las posiciones teóricas y legales anteriores puede definirse a la cooperativa como la agrupación de personas integrada voluntariamente, de naturaleza jurídica especial. Posee objetivos culturales, sociales y económicos que se alcanzan mediante la realización de actividades empresariales (empresa cooperativa) democráticamente gestionadas.

Como rasgos característicos esenciales de las cooperativas pueden sostenerse: la estructura y gestión democrática, ${ }^{27}$ la realización sui generis de una actividad empresarial, la existencia de necesidades socioeconómicas comunes a todos los socios, actuación guiada por una serie de principios y carácter instrumental del capital y patrimonio con respecto a la persona.

\section{El capital social cooperativo: sus funciones. Distinción de las que cumple en una sociedad mercantil}

Tal como advierte Viguera Revuelta los primeros cooperativistas, movidos por consideraciones ideológicas y de carácter socio- económico, construyeron el proyecto de empresa cooperativa sobre el esquema de la eliminación del capital social, (...). Pese a ello, es una orientación hace tiempos abandonada. En la actualidad, (...) se parte de la necesidad de dotar a estas figuras de un capital... ${ }^{28}$

Por tanto, las cooperativas como cualquier otra organización colectiva necesitan de recursos económicos para cumplir sus fines. Estos pueden ser aportados por los socios e integrar su capital social. Esto no significa desconocer las particularidades de las cooperativas frente a las sociedades mercantiles. La necesidad de dotarlas de recursos patrimoniales no desvirtúa su especialidad jurídica distinta, es independiente del reconocimiento de su naturaleza acapitalista y antiespeculativa. ${ }^{29}$

Por tanto, no existe equivalencia alguna entre el capital social de las sociedades mercantiles y el de las cooperativas, consecuencia también de la divergente naturaleza de unas y otras, son distintos y por tanto requieren conceptos también distintos. No obstante, es induda-

27 Reyes, Las especiales..., 6.

28 Rodrigo Viguera Revuelta, «El derecho de reembolso en las sociedades cooperativas». (Tesis Doctoral, Universidad de Sevilla, (Inédita).,2011): 55.

29 Rodrigo, El derecho..., 55 
ble la necesidad de acudir a la doctrina mercantil que supone un importante referente en este sentido.

Vicent Chuliá define el capital social cooperativo como el conjunto de las aportaciones de los socios, para (...) las cooperativas la suma representativa en el pasivo de las aportaciones de socios y asociados, desembolsadas o prometidas... ${ }^{30}$

Este autor introduce un elemento de especial controversia en torno a la naturaleza del capital social y es lo que se refiere a su carácter de pasivo, criterio este que no compartimos. Aunque puede reconocerse un interés limitado al capital y/o devolución del aporte realizado, no es una forma de propiedad individual, pues en realidad pertenece a la cooperativa como parte de su patrimonio y aunque el socio pudiera recuperarlo, siempre lo hará bajo determinadas condiciones que no pongan en riesgo la organización colectiva.

Otro de los elementos a analizar de tal definición es el hecho de que las aportaciones pueden estar «desembolsadas o prometidas». Ello se desprende de la posibilidad de aportar de manera fraccionada, dando lugar al capital suscrito o prometido y al capital integrado.

Ahora bien, el capital social cooperativo posee carácter variable, consecuencia del principio de puertas abiertas, la posibilidad de que realicen aportaciones voluntarias y la exigencia de nuevas aportaciones obligatorias. En este propio sentido Fajardo García ha dicho: el capital social de la cooperativa posee naturaleza variable. ${ }^{31}$

El capital social cooperativo constituye, entonces, la cifra resultante de la suma de las aportaciones de los socios. Posee carácter variable, lo que unido a las funciones que cumple, contribuye a delimitar la particular identidad de las cooperativas.

La singularidad del capital social cooperativo con respecto al capital social en las sociedades mercantiles presupone que las funciones que este cumple sean sustancialmente distintas de las que asume en las sociedades mercantiles.

Las funciones del capital social son de interés jurídico y económico, y aunque se han estudiado y sistematizado principalmente en relación con las sociedades mercantiles ${ }^{32}$ también se configuran en las cooperativas, aunque con determinadas particularidades.

30 Francisco Vicent Chuliá, Compendio crítico de Derecho Mercantil. 2C ed. Tomo I Editorial. Bosch, Barcelona 1986: 570

31 Gemma Fajardo García, "La gestión económica de la cooperativa. Responsabilidad de los socios» (tesis doctoral, Universidad de Valencia, 1997): 7, https://dialnet.unirioja.es/servlet/tesis?codigo $=88127$

32 Fajardo, La gestión...,13. 
Según Massaguer el capital social en la sociedad anónima cumple tres funciones: la de garantía, la organizativa, y la función empresarial. ${ }^{33}$ Pese a que la misión del capital social cooperativo responde a una filosofía distinta y a unas funciones diferentes a aquellas que desempeña en las sociedades de capitales ${ }^{34}$, se tomarán como referencia para abordar dicha temática.

En el caso de las cooperativas, la función de garantía no opera de la misma manera. El capital social cooperativo no cumple esta función porque no se exige su mención en los estatutos, y por lo tanto no se garantiza su conocimiento por los acreedores 35 . Sin embargo, distinto sucede en el caso del capital social mínimo que al estar reconocido en los estatutos opera como límite mínimo a la variabilidad del capital y de esta forma sirve de garantía a los acreedores y los aportadores. Pero al final, el capital mínimo es capital social, es su borde inferior, su límite. Por tanto, si tomamos en cuenta esta última cuestión, el capital social si cumple esta función en las cooperativas.

No obstante, según Algorta Morales y Amorín, en puridad esta función no es tal, ya que el verdadero respaldo de los acreedores es el patrimonio social ${ }^{36}$. Sin embargo, en nuestro criterio, lo anterior es parcialmente correcto pues el patrimonio cooperativo ${ }^{37}$ en su conjunto, es la expresión superior de garantía para los terceros, es la muestra de la total gestión económica. Pero no es incorrecto sostener que el capital posee también esta función, es parte del patrimonio, además, tal como se dijo antes, actúa como límite a la variabilidad de este (capital mínimo), sirviendo entonces como garantía.

33 José Massaguer, «El capital nominal. Un estudio del capital de la Sociedad anónima como mención estatutaria». R. G. D. nQ 550- 551, Julio- agosto (1990): 5549, www.redalyc.org.

34 Carmen Pastor Sempere, "La reforma del Derecho Cooperativo y su repercusión en el régimen de los recursos propios». (tesis presentada en opción al Grado de Doctor. Universidad de Alicante, 1999): 417, rua.ua.es

35 Fajardo, La gestión...,32.

36 Marcelo Amorín y Paula Algorta Morales, Sociedades Cooperativas Sistema y Derecho Cooperativo, Montevideo, (Editorial La Ley, 2010): 290, https://pmb.parlamento. gub.uy/pmb/opac_css/index.php?|v|=notice_display\&id=67866

37 Con el fin de reforzar el fin garantista del patrimonio cooperativo se les exige a las cooperativas constituir fondos obligatorios que la fortalezcan patrimonialmente. Al decir de García Ordaz la aplicación estricta de este principio (variabilidad) podría suponer una reducción de la garantía que para terceros supone una cierta estabilidad de la cifra de capital, para paliarlo en parte, las leyes regulan otros fondos que con dotación obligatoria y de carácter irrepartible hagan que la estructura de fondos propios de la cooperativa adquiera entidad propia. Mercedes García Ordaz, "Análisis desde la perspectiva contable de las cooperativas agrícolas andaluzas». (Memoria para optar al grado de doctora, 2010), 220, http://dialnet.unirioja.es 
Coincidimos con Galgano, cuando sostuvo que el capital social tiene la función de expresar la entidad mínima de esta garantía ${ }^{38}$.

En segundo lugar, el capital social cooperativo se destina al cumplimiento del objeto social. Cumple una función empresarial o de productividad. Visto así, el capital social tiene el propósito de ser utilizado como capital de explotación por la cooperativa, pues es un vehículo que les permite participar dentro del mercado ${ }^{39}$ y cumplir el fin por el que fueron creadas.

Por último, el capital social tiene una función organizativa. Tal como advierten Broseta Pont y Martínez Sanz, ... en la sociedad anónima la proporción y la estructura del reparto del capital condicionan decisivamente su propio control y su dominio y, porque la intensidad en el ejercicio de los derechos sociales de los socios depende básicamente del número de acciones (es decir, del capital) que se posea ${ }^{40}$. En ellas, como en el resto de las sociedades capitalistas, el capital es la esencia misma de la sociedad. El capital social (...) funciona a su vez como técnica de organización jurídica de la empresa ${ }^{41}$, por una parte, determina la estructura financiera y orgánica de la sociedad y por otra presupone la posición jurídica de los socios en la gestión social.

En el caso de las cooperativas, esta función opera de manera distinta. En torno al primero de estos aspectos - estructura financierahay que advertir que aquí el capital no posee dicha función. Este no determina la existencia o no de beneficios, estos dependen de la constitución de las reservas que con carácter obligatorio exige la ley.

En cuanto a la influencia del capital en la estructura orgánica, hay que comenzar diciendo, tal como señala Fajardo García, en la sociedad anónima, el capital social, sirve de referencia para determinar la constitución y composición de los órganos sociales ${ }^{42}$. En la cooperativa, por el contrario, la estructura y funcionamiento de los órganos sociales no depende del capital social, sino de los propios socios, rige como regla general el principio de igualdad que se traduce en un socio un voto.

38 Francesco Galgano, Derecho Comercial. Volumen I/ «Las Sociedades». Temis, Bogotá, 1999: 208.

39 Lina Henao, «Hacia un nuevo modelo de capital social» Revista de Derecho Privado, Universidad Externado de Colombia, n. ${ }^{\circ} 28$, julio-diciembre de (2014): 237-273, https://revistas.uexternado.edu.co/index.php/derpri/article/view/4131

40 Manuel Broseta Pont y Fernando Martínez Sanz, Manual de Derecho Mercantil. Volumen I, 17 Edición. Editorial Tecnos, Madrid, 2010: 353.

41 Fajardo, La gestión...,14.

42 Fajardo, La gestión....23. 
En torno al último aspecto de esta función -estructura corporativa- el capital social no cumple esta función de igual manera en las cooperativas que en las sociedades mercantiles. El socio de una sociedad comercial ejerce sus derechos políticos y económicos en forma proporcional a su participación en el capital. Frente a esta situación, en la cooperativa la aportación del socio no determina la medida de sus derechos políticos, ni económicos ${ }^{43}$.

Si embargo, no puede decirse que el capital no tiene ninguna relevancia sobre los derechos y obligaciones de los socios. En este sentido, el socio cooperativo con su aportación, perfecciona el derecho a ser socio de la cooperativa, puede participar en la actividad económico-social de la misma, actualiza sus propias aportaciones y puede cobrar intereses por las mismas. Por tanto, la influencia del capital es parcial no inexistente.

También en la cooperativa, el capital social cumple la función de limitar la responsabilidad máxima de los socios, por supuesto cuando esta adopta la forma de responsabilidad limitada, en estos casos los socios sólo responden con sus aportaciones al capital social. Esto prueba otra forma de influencia del capital sobre los derechos y obligaciones de los socios en la cooperativa.

Lo anterior corrobora que el capital social, aunque necesario en las cooperativas, no posee la misma connotación que en las sociedades mercantiles. Esto influye directamente en el carácter también distinto de la empresa cooperativa y su identidad en materia patrimonial.

\section{El capital social cooperativo: aciertos y desaciertos de su novísima regulación en Cuba}

Las cooperativas en Cuba, son relativamente recientes, su desarrollo exponencial ocurrió tras el triunfo revolucionario de 1959. Igual sucede en materia legal, pues anterior a ello, se regulaban por normas de carácter general.

Pese al desarrollo en la etapa revolucionaria, hasta el 2012 las cooperativas en Cuba solo tenían cabida en el sector agropecuario. El movimiento cooperativo hasta ese entonces se integraba por las Cooperativas de Producción Agropecuaria (CPA), las Cooperativas de Créditos y Servicios (CCS) y las Unidades Básicas de Producción Cooperativa

43 Francisco Vicent Chuliá, "Análisis Crítico del nuevo Reglamento de la cooperación». RDM N. ${ }^{\circ}$ 125-126, (1972): 465, https://dialnet.unirioja.es/servlet/articulo?codigo=6456494 
(UBPC). Las mismas, aunque con diferentes formas de organización y funcionamiento solo se vinculan al sector agrario, esto limitaba sobremanera la utilidad de las cooperativas en general.

Sin embargo, el 15 de noviembre de 2012 se aprobó el DecretoLey N. ${ }^{\circ} 305$ «De las Cooperativas no Agropecuarias» y sus normas complementarias, estas sustentaron la constitución de cooperativas en sectores distintos del agrario.

La extensión del cooperativismo a esferas no agropecuarias de la producción y los servicios, constituyó - y constituye - uno de los mayores retos del proceso de actualización del modelo económico cubano (...), por la necesaria superación de las deficiencias expresadas, durante años, en las cooperativas del sector agrícola, la discordancia entre el ser y el deber ser de las cooperativas como forma superior de organización y gestión colectiva para la producción de bienes o la prestación de servicios en una sociedad en transición al socialismo ${ }^{44}$.

Dichas normas marcaron un renacer del cooperativismo en Cuba, ya que ampararon la constitución de cooperativas en sectores claves como el constructivo, el transporte, la recuperación de materias primas, etc. Sin embargo, dicho marco jurídico no estuvo exento de desaciertos y cuestionamientos. Estos pueden sistematizarse en:

- Incongruencia con la Constitución de la República de Cuba vigente en ese entones, ya que esta solo reconocía de manera expresa el derecho a asociarse en cooperativas a los agricultores pequeños, estableciendo, además, solo como forma de propiedad la cooperativa agraria.

- Se reconoce a la cooperativa como organización sin delimitar su particular naturaleza jurídica.

- Complejo y dilatado proceso para la aprobación de una cooperativa no agropecuaria, requiriendo de la intervención de órganos administrativos a nivel nacional, sin un plazo de duración delimitado constituyendo esto una causa de desestimulo para aspirantes a socios cooperativistas.

- Se priorizó la transformación de empresas estatales en cooperativas, lo que se conoce como cooperativismo inducido, en algunos casos sin previa sensibilización y educación, lo que limitó el principio de voluntariedad.

44 Yulier Campos Pérez, y Liuva León García, "Análisis crítico a las obligaciones contraídas en el período de formación de las cooperativas no agropecuarias en Cuba», BAIDC, Boletín de la Asociación Internacional de Derecho Cooperativo. No 51, (2017): 263, http://baidc.revistas.deusto.es/issue/viewlssue/201/74 
- Incongruencias en el régimen jurídico-económico de las cooperativas las que se expresan fundamentalmente en la concepción del capital de trabajo inicial y los fondos cooperativos.

A siete años de su puesta en vigor el marco jurídico anterior — tal como se puntualizó antes - ha sido derogado y en su lugar han sido promulgadas las siguientes disposiciones jurídicas:

Decreto Ley No. 366 «De las Cooperativas No Agropecuarias» (DL), Decreto No. 356 «Reglamento de las Cooperativas No Agropecuarias» (D), Resolución No. 36 de la Ministra de Finanzas y Precios, sobre el tratamiento de precios, tributario, financiero y contable de las cooperativas no agropecuarias, Resolución No. 362 de la Ministra de Finanzas y Precios, respecto al pago del Impuesto sobre Ingresos Personales de los trabajadores contratados. ${ }^{45}$

Este marco jurídico recién aprobado actualiza las normas jurídicas cooperativas no agropecuarias generales en Cuba, no obstante, subsisten cuestiones que escapan del mismo, esto se debe en gran medida, a la inexistencia de una norma cooperativa general que delimite los elementos básicos a las mismas, sin importar su tipología (agropecuaria o no). En la actual etapa por la que atraviesan las cooperativas en Cuba, prima la voluntad política de favorecer un proceso para su expansión hacia otras esferas de la economía nacional además de la agropecuaria. Sin embargo, como resultado de las limitaciones de la plataforma jurídico-institucional (...) se vienen presentando dificultades que podrían distorsionar, de modo sustancial, el redimensionamiento del sector...46

La cuestión del capital social cooperativo no escapa de esta problemática, pues la propia asistematicidad general del ordenamiento cooperativo nacional incide sobre la figura, al igual como en otras tantas.

En lo adelante se sigue la propia lógica del ordenamiento cubano, delimitando las principales particularidades (aciertos y desaciertos) que posee la regulación cubana en materia de capital social cooperativo, así como algunas propuestas en pos de su perfeccionamiento.

Siguiendo esta lógica el mencionado Decreto Ley conceptualiza que entender por cooperativa no agropecuaria en Cuba, a los efectos delimita que «(...) se constituye voluntariamente sobre la base del aporte de bienes y derechos y se sustenta en el trabajo de sus socios». (art. 2.1). Desde esta disposición general se reconoce la posibilidad de

45 Todas publicadas en la Gaceta Oficial No. 63 Ordinaria de 30 de agosto de 2019.

46 Orestes Rodríguez Musa, Presupuestos teóricos para el redimensionamiento constitucional de la cooperativa en Cuba, (Tesis presentada en opción al Grado Científico de Doctor en Ciencias Jurídicas, La Habana, 2016): 91 
aportar bienes y derechos, cuestión atinada pues ambos elementos pueden cumplir los fines del capital y el patrimonio.

Las cooperativas en este ámbito se pueden organizar de tres formas distintas; pueden constituirse a partir de los aportes dinerarios de personas naturales que deciden voluntariamente asociarse entre sí, donde los miembros puedan organizar un patrimonio colectivo o aun conservando la propiedad individual de todos los bienes, aunque gestionándolos de manera conjunta. También pueden formarse a partir del patrimonio estatal, u organizándose de manera mixta, es decir, combinando alguna de las formas anteriores. Aunque los aportes de los socios pudieran efectuarse en cualquier tipo, no es menos cierto que tal fórmula se ha pensado para aquellas que parten del interés privado o individual y no en las inducidas donde los recursos económicos, proceden esencialmente del Estado. Esto último no tiene que ser así en todos los casos pues los aspirantes a socios pudieran en cualquier variante aportar dinero u otros bienes o derechos, de esta manera se contribuye al funcionamiento de la cooperativa, además favorece al compromiso individual de trabajar colectivamente.

En torno al tema del régimen económico y especialmente el capital social, las normas cooperativas para sectores distintos del agropecuario establecen la obligatoriedad para constituirse de contar con un capital de trabajo inicial (lo que sería estrictamente hablando capital social inicial). Sin embargo, no reconoce la existencia de un capital mínimo cuestión esta que atenta contra las funciones del capital social; en especial la función de garantía, pues la cifra podrá ser formal y no poseer utilidad en la práctica.

Los aportes que integran el capital podrán realizarse en dinero (aportes dinerarios) y en otros bienes y servicios (art. $42 \mathrm{DL}$ ). En el caso de los primeros no se delimita en que moneda se aceptarían. Además, se dice que solo podrá aportarse dinero al momento inicial de constituir la cooperativa (art. 44.5 DL), elemento este que a nuestro criterio limita la exigencia de nuevos aportes en dinero y también de aportes voluntarios.

En este propio sentido, la norma ha querido impedir la existencia de meros socios inversores, o que haya privilegios o supremacía por aquellas personas de más contribución económica. Vale recordar que en las cooperativas el capital tiene un fin instrumental, está al servicio de la persona. Sin embargo, tal limitación no es adecuada pues puede resultar más ventajoso para las cooperativas en determinados casos acudir a nuevas aportaciones obligatorias o voluntarias dinerarias y no a otras fuentes de financiamiento (créditos bancarios) con la exigencia de los correspondientes intereses, por solo citar un ejemplo. 
En otro orden, y acertadamente, se establece que los actos de disposición sobre bienes y derechos que integran el patrimonio (incluye al capital social) requieren la aprobación de la Asamblea General (art. $45 \mathrm{DL}$ ). Esto se refuerza en materia patrimonial con el hecho de que ante la pérdida de la condición del socio la asamblea determinará si procede o no la devolución del aporte dinerario inicial y condiciones para su realización (art. 25 g) D), sin embargo, no se hace referencia a quién decide el destino de las otras aportaciones que pueden realizarse y que son distintas del dinero. Constituye un elemento que podrá delimitarse en los estatutos de la cooperativa en particular a fin de evitar posibles conflictos. La inclusión de este elemento se justifica en el hecho de que el estatuto tiene una parte obligatoria y otra facultativa. Normalmente la ley establece la obligación de incorporar ciertas disposiciones en el estatuto, además de otras de carácter facultativo. Con ello, deja una gran libertad para determinar los derechos y obligaciones de los miembros, bajo reserva de no contradecir los principios esenciales de la ley y las disposiciones obligatorias que puedan imponer el estatuto-tipo, si lo hubiese y tuviere el carácter de obligatorio ${ }^{47}$.

Por último, es necesario puntualizar que las normas de referencia no establecen con carácter obligatorio como una causal de extinción la pérdida del capital social, caso contrario a si los estatutos lo prevén tal como se establece en el art. 58 a) DL. La no inclusión como causal de extinción de tal situación está en consonancia con la no exigencia de un capital mínimo, la inexistencia de este último presupone lo primero.

Visto lo referente al cooperativismo no agropecuario, tal como sucedió con su marco jurídico, las normas reguladoras del fenómeno se han actualizado también en el 2019 para las cooperativas agrarias.

El nuevo marco regulatorio se integra por el Decreto-Ley No. 365 «De las Cooperativas Agropecuarias» (DLAg) y el Decreto 354 Reglamento del Decreto-Ley de las Cooperativas Agropecuarias (DAg)48. Tales normas derogaron de manera total a la Ley No. 95 «De las Cooperativas de Producción Agropecuaria y de Créditos y Servicios», de 2 de noviembre de 2002, el Decreto-Ley No. 142 «Sobre las Unidades Básicas de Producción Cooperativa», de 20 de septiembre de 1993, el Acuerdo No. 5454, de 17 de mayo de 2005, que aprobó los reglamentos generales de las cooperativas de producción agropecuaria y las cooperativas de créditos y servicios, el Acuerdo No. 7271, de 19

47 Alberto, Derecho..., 3.

48 Ambas publicadas en la Gaceta Oficial No. 37 Ordinaria de 24 de mayo de 2019. 
de julio de 2012, sobre unidades básicas de producción cooperativa, ambos del Comité Ejecutivo del Consejo de Ministros, y la Resolución No. 574, de 13 de agosto de 2012, del ministro de la Agricultura, que aprobó el Reglamento General de las unidades básicas de producción cooperativa.

Las actuales disposiciones jurídicas, representan un paso de avance en la regulación cooperativa cubana, en tanto, regulan en un solo cuerpo jurídico los tres tipos de cooperativas agrarias cubanas.

Referente al capital social cooperativo es necesario puntualizar que dichas normas no reconocen expresamente dicha institución, no obstante, cuando regulan al patrimonio cooperativo establece cuestiones que se refieren al capital social y no al patrimonio.

Las cooperativas agrarias «se constituyen sobre la base del aporte de bienes y trabajo de sus cooperativistas, posee personalidad jurídica, patrimonio propio...» (Art. 2.3 DLAg). Lo anterior refuerza la importancia de los aportes de los socios cooperativistas, pero introduce cierta confusión en relación a los mismos y es el hecho de que se pueden aportar bienes y trabajo, pero no delimita en qué condición.

En el caso del marco jurídico objeto de análisis, reconoce como un requisito para ser socio «estar apto para realizar labores productivas o de servicios» o lo que es lo mismo; trabajar (art. 45 c) DLAg). Pareciera que, acertadamente, se reconoce el trabajo como requisito y no como aportación patrimonial, sin embargo, en ese propio artículo, se incluye otro requisito que establece la obligatoriedad de «aportar a la cooperativa agropecuaria bienes o trabajo» (art. 45 d) DLAg), por tanto, la confusión se mantiene puesto que cuándo se aporta trabajo como requisito y cuándo como contribución patrimonial. Se debió solo reconocer al trabajo como requisito independiente y no además como contribución patrimonial.

De la revisión de tales normas jurídicas destacan, en materia de capital social, los siguientes elementos:

- Exclusión de la aportación de derechos al capital social pese a que los mismos tengan contenido patrimonial. Esto restringe sobremanera las aportaciones al capital social y la propia gestión colectiva.

- Indivisibilidad del patrimonio pues el mismo no puede ser objeto de división o repartición entre los cooperativistas, excepto en los procesos de extinción en que resulte procedente (art. 8 e) DLAg). Lo anterior con marcado carácter absoluto limita el derecho de reembolso por parte de los cooperativistas que resulten baja de la cooperativa de las aportaciones realizadas. 
- La Asamblea General es el órgano encargado de la aprobación de cualquier acto de disposición sobre los bienes propiedad de la cooperativa, con exclusión de la tierra y otros bienes que presentan régimen especial o regulaciones específicas para ser objeto de cualquier acto traslativo de dominio (art. 11 DLAg), tal es el caso de los tractores, las viviendas y el ganado mayor.

- En el caso de la CPA el socio aportador tiene derecho al pago de la amortización por los bienes aportados, la que no constituye un precio al igual que en un contrato de compraventa pues la aportación es un acto jurídico distinto de esta. Esto se refuerza en el caso de la UBPC y la CPA con el hecho de reconocer como elementos patrimoniales distintos a las aportaciones y los bienes adquiridos por compraventa o cualquier otro título. El derecho de los aportantes se transmite a los herederos o en caso de baja.

- Los bienes objeto de aportación deben ser valuados de acuerdo a las tarifas establecidas oficialmente. Dicha valuación debe incluirse en el expediente de constitución (art. 4.2 DAg).

- En caso de disolución el activo resultante de la liquidación se destina entre otras cuestiones a pago de las amortizaciones pendientes a los aportadores, no se devuelven la atierra y demás bienes agropecuarios al socio aportador.

En otro orden, la norma reconoce los tres tipos de cooperativas agrarias existentes en el país; las Cooperativas de Producción Agropecuaria (CPA), las Unidades Básicas de Producción Cooperativa (UBPC) y las Cooperativas de Créditos y Servicios (CCS). No obstante, y pese a reunir en un solo cuerpo normativo tales cooperativas, la regulación de las mismas sigue siendo diversa, lo que se debe a las singularidades de tales cooperativas. En cuanto al patrimonio, y particularmente al capital social, la diversidad se acentúa.

\section{Conclusiones}

En base a lo analizado anteriormente se puede concluir que:

1. La cooperativa desde el punto de vista jurídico es la agrupación de personas integrada voluntariamente, de naturaleza jurídica especial, distinta de la asociación y la sociedad. Posee objetivos culturales, sociales y económicos que se alcanzan mediante la realización de actividades empresariales (empresa cooperativa) democráticamente gestionadas; esto justifica su «doble naturaleza». 
2. Los rasgos característicos esenciales de las cooperativas son: la estructura y gestión democrática, la realización sui generis de una actividad empresarial, la existencia de necesidades socioeconómicas comunes a todos los socios, actuación guiada por una serie de principios y carácter instrumental del capital y patrimonio con respecto a la persona. Esto último tributa a su especial identidad en materia económica.

3. El capital social cooperativo constituye la cifra resultante de la suma de las aportaciones de los socios. Posee carácter variable e ilimitado. La singularidad del capital social cooperativo con respecto al capital social en las sociedades mercantiles presupone que las funciones que este cumple sean sustancialmente distintas de las que asume en aquellas. Esto se configura especialmente en la función organizativa y la de garantía.

4. Las cooperativas en Cuba, son relativamente recientes, su desarrollo exponencial ocurre tras el triunfo revolucionario de 1959. Sin embargo, pese a este desarrollo en la etapa revolucionaria hasta el 2012 las cooperativas en Cuba solo tenían cabida en el sector agropecuario. A ello se unen las deficiencias que desde su régimen jurídico menoscaban su identidad en el contexto nacional.

5. El ordenamiento jurídico cooperativo en Cuba se caracteriza por su asistematicidad puesto que el mismo varía en dependencia del objeto de la cooperativa, sea esta agropecuaria o no. Dicha asimetría incide sobre las instituciones jurídico cooperativas, tal es el caso del capital social y los elementos que lo conforman, su regulación varía desde su no reconocimiento expreso en materia agropecuaria hasta limitaciones técnicas en sede no agraria. Ello entorpece la noción uniforme de la figura y el abordaje jurídico de sus principales derroteros.

\section{Bibliografía y legislación}

\section{Textos y documentos}

AMORÍN, Marcelo y ALGORTA MORALES, Paula. 2010. Sociedades Cooperativas Sistema y Derecho Cooperativo, Montevideo, Editorial La Ley, 2010. https://pmb.parlamento.gub.uy/pmb/opac_css/index.php?|v|=notice_ display\&id=67866

ARANZADI TELLERÍA, Dionisio. 1994. "Los valores cooperativos en el umbral del año 2000», Anuario de Estudios Cooperativos, Bilbao. 
ATXABAL RADA, Alberto. 2018. «Los impuestos personales sobre el capital en las cooperativas y en sus socios en el País Vasco». Boletín De La Asociación Internacional De Derecho Cooperativo, n. ${ }^{\circ} 52$ (julio), 137-66. https://doi. org/10.18543/baidc-52-2018pp137-166.

BRETOS, I., Díaz-Foncea, M., MARCUELLO, C., \& Marcuello, C. 2018. Cooperativas, capital social y emprendimiento: Una perspectiva teórica. REVESCO. Revista De Estudios Cooperativos, 128, 76-98. https://doi. org/10.5209/REVE.59775

BROSETA PONT, Manuel y Martínez Sanz, Fernando. 2010. Manual de Derecho Mercantil. Volumen I, 17 Edición. Editorial Tecnos, Madrid.

CAMPOS PÉREZ, Yulier y LEÓN GARCÍA, Liuva. 2017. "Análisis crítico a las obligaciones contraídas en el período de formación de las cooperativas no agropecuarias en Cuba», BAIDC, Boletín de la Asociación Internacional de Derecho Cooperativo. No 51. DOI: https://doi.org/10.18543/baidc-512017pp261-285.

CAMPOS PÉREZ, Yulier. 2018. «El Capital Social Cooperativo Como manifestación Del Principio De participación económica. Análisis teóricoLegal En Cuba». Boletín De La Asociación Internacional De Derecho Cooperativo, n. ${ }^{\circ} 53$ (diciembre), 173-205. https://doi.org/10.18543/baidc53-2018pp173-205.

CASTÁN TOBEÑAS, José. 1985. Derecho civil español. Común y foral, t. IV, Editorial. Reus, Madrid.

DÍEZ-PICAZO, Luis y GULLÓN, Antonio. 1999. Sistema de Derecho Civil, Vol. II, Editorial. Tecnos.

FAJARDO GARCÍA, Gemma. 1997. «La gestión económica de la cooperativa. Responsabilidad de los socios». Tesis doctoral, Universidad de Valencia. https://dialnet.unirioja.es/servlet/tesis?codigo=88127

GADEA, Enrique, SACRISTÁN, Fernando y VARGAS, Carlos. 2009. Régimen jurídico de la sociedad cooperativa del siglo XXI. Realidad actual y propuestas de reforma, Editorial Dykinson, Madrid.

GALGANO, Francesco. 1999. Derecho Comercial. Volumen II «Las Sociedades». Temis, Bogotá.

GARCÍA MÜLLER, Alberto. 2019. Derecho Cooperativo y de la economía social y solidaria, Editorial Mérida, Buenos Aires.

GARCÍA ORDAZ, Mercedes. 2010. "Análisis desde la perspectiva contable de las cooperativas agrícolas andaluzas». Memoria para optar al grado de doctora. http://dialnet.unirioja.es

HENAO, Lina. 2014. "Hacia un nuevo modelo de capital social» Revista de Derecho Privado, Universidad Externado de Colombia, n. ${ }^{\circ} 28$. https://revistas. uexternado.edu.co/index.php/derpri/article/view/4131

HERNÁNDEZ AGUILAR, Orisel, Orestes RODRÍGUEZ MUSA, y Martha BEATRIZ MARTÍNEZ DE OSABA FONTANELLA. 2019. "La auto-regulación en las cooperativas no agropecuarias cubanas. propuestas para su optimización mediante la asesoría jurídica». Boletín De La Asociación Internacional De Derecho Cooperativo, n. 55 (diciembre), 105-33. https://doi. org/10.18543/baidc-55-2019pp105-133. 
HERNÁNDEZ SALAZAR, G. A., OLAYA PARDO, A. M., \& TORRES GUEVARA, L. E. 2020. Heterogeneidad de los asociados y estructura de capital de las cooperativas no financieras en Colombia. REVESCO. Revista De Estudios Cooperativos, 135, e69178. https://doi.org/10.5209/reve.69178

LAGOS RODRÍGUEZ, Begoña. 2020. «Propuesta De regulación De La aportación Al Capital Social En La Sociedad Cooperativa española: Aportación Dineraria Y aportación No Dineraria». Boletín De La Asociación Internacional De Derecho Cooperativo, n. ${ }^{\circ} 56$ (abril), 107-55. https://doi. org/10.18543/baidc-56-2020pp107-155.

MASSAGUER, José. 1990. «El capital nominal. Un estudio del capital de la Sociedad anónima como mención estatutaria». R. G. D. n. ${ }^{\circ}$ 550- 551.

MESA TEJEDA, Natasha Teresa. 2014. "Reflexiones críticas en torno a la regulación de las cooperativas no agropecuarias en Cuba», Boletín de la Asociación Internacional de Derecho Cooperativo No. 48, Universidad de Deusto, Bilbao, DOI: https://doi.org/10.18543/baidc-48-2014pp227-243.

NARANJO MENA, Carlos. 2018. "Concepto y naturaleza jurídica de la cooperativa», en Derecho Cooperativo Latinoamericano, ed. por José Ernani de Carvalho Pacheco, Curitiba, Juruá Editora.

PASTOR SEMPERE, Carmen.1999. "La reforma del Derecho Cooperativo y su repercusión en el régimen de los recursos propios». Tesis presentada en opción al Grado de Doctor. Universidad de Alicante.

REYES LAVEGA, Sergio. 2012. Las especiales características de las cooperativas. Fundación Friedrich Ebert, República Dominicana.

RODRÍGUEZ MUSA, Orestes. 2016. Presupuestos teóricos para el redimensionamiento constitucional de la cooperativa en Cuba. Tesis presentada en opción al Grado Científico de Doctor en Ciencias Jurídicas, La Habana.

SÁNCHEZ-COLL, S. 2020. "El capital social local y sus determinantes: evidencia de Cataluña», CIRIEC-España, Revista de Economía Pública, Social y Cooperativa, 99, 203-232. DOI: 107203/CIRIEC-E.99.15706.

VICENT CHULIÁ, Francisco. 1972. "Análisis Crítico del nuevo Reglamento de la cooperación». RDM N. ${ }^{\circ}$ 125- 126. https://dialnet.unirioja.es/servlet/ articulo? codigo $=6456494$

VICENT CHULIÁ, Francisco. 1986. Compendio crítico de Derecho Mercantil. 2C ed. Tomo I Editorial. Bosch, Barcelona.

VIGUERA REVUELTA, Rodrigo. 2011. «El derecho de reembolso en las sociedades cooperativas». Tesis Doctoral, Universidad de Sevilla, (Inédita).

\section{Legislación}

Constitución de la República de Cuba proclamada el 10 de abril de 2019. Gaceta Oficial No. 5 Extraordinaria de 10 de abril de 2019

Lei n. 119/2015 Código Cooperativo Portugal de 31 de agosto. De la Asamblea de la República de Portugal, de 31 de agosto de 2015. (Diario de la República n. ${ }^{\circ}$ 169/2015). 
LEI N. 5.764 (Official Gazette, 1971-12-16, 40p. (COOP) de 16 de diciembre de 1971.

Ley Cooperativa Alemana, de 19 de agosto de 1994, recuperada de http:// www.dgrv.org/

Ley de Cooperativas de España, Ley 27, de 16 de julio de 1999. (BOE núm. 170, de 17 de julio de 1999).

Ley de Cooperativas en Honduras (Decreto No. 146 de 2019) (Diario Oficial de la Republica de Honduras).

Ley N. ${ }^{\circ} 18.407$ Sistema Cooperativo. República Oriental del Uruguay. De la Cámara de Senadores, de fecha 24 de octubre de 2008. (Diario Oficial N. ${ }^{\circ} 27612$ de 14 noviembre de 2008).

Decreto-Ley No. 365 «De las cooperativas agropecuarias» de 22 de octubre de 2018. Gaceta Oficial No. 37 Ordinaria de 24 de mayo de 2019.

Decreto-Ley No. 366 «De las cooperativas no agropecuarias» de 19 de noviembre de 2018. Gaceta Oficial No. 63 Ordinaria de 30 de agosto de 2019.

Decreto-Ley N. ${ }^{\circ} 305$ «De las Cooperativas no Agropecuarias» de fecha 15 de noviembre de 2012. Gaceta Oficial 053 Extraordinaria de 11 de diciembre de 2012.

Decreto No. 354 «Reglamento del Decreto-Ley de las cooperativas agropecuarias» de 18 de diciembre de 2018. Gaceta Oficial No. 37 Ordinaria de 24 de mayo de 2019.

Decreto No. 356 «Reglamento de las cooperativas no agropecuarias» de 2 de marzo de 2019 Gaceta Oficial No. 63 Ordinaria de 30 de agosto de 2019. 


\section{Derechos de autor}

El Boletín de la Asociación Internacional de Derecho Cooperativo es una revista de acceso abierto lo que significa que es de libre acceso en su integridad inmediatamente después de la publicación de cada número. Se permite su lectura, la búsqueda, descarga, distribución y reutilización legal en cualquier tipo de soporte sólo para fines no comerciales y según lo previsto por la ley; sin la previa autorización de la Editorial (Universidad de Deusto) o el autor, siempre que la obra original sea debidamente citada (número, año, páginas y DOI si procede) y cualquier cambio en el original esté claramente indicado.

\section{Copyright}

The International Association of Cooperative Law Journal is an Open Access journal which means that it is free for full and immediate access, reading, search, download, distribution, and lawful reuse in any medium only for non-commercial purposes, without prior permission from the Publisher or the author; provided the original work is properly cited and any changes to the original are clearly indicated. 